\title{
Retrospective Analysis of the One-per-Million Tumescent Technique in Post-Burn Hand Deformity Surgeries
}

\author{
Theddeus OH Prasetyono ${ }^{1}$, Astrid Felicia Koswara ${ }^{2}$ \\ ${ }^{1}$ Division of Plastic Surgery, Department of Surgery, Faculty of Medicine, University of Indonesia and Cipto Mangunkusumo Hospital, \\ Jakarta; ${ }^{2}$ Diponegoro 71 Jakarta 13410, Jakarta, Indonesia
}

Background The use of a tourniquet in hand surgery is generally accepted as necessary to create a clear visualization of the operative field. This study aims to determine the effectiveness of one-per-million tumescent solution (1:1,000,000 epinephrine concentration) in creating a bloodless operative field in post-burn hand deformity surgeries performed without a tourniquet.

Methods This retrospective observational study was conducted on a series of 12 patients with post-burn hand deformities who underwent surgery between February 2013 and January 2014. A total of 29 operative fields were recorded. The one-per-million tumescent solution was used for hemostatis instead of a tourniquet. The clarity of the operative field, volume of solution injected, duration of surgery, scar thickness and density, and functional outcomes at least three months after the surgery were observed. The relationship of scar thickness and density with the clarity of the operative field was analyzed with the chi-square test.

Results 0 the 29 operative fields in which the one-per-million tumescent technique was used, $48.2 \%$ were totally bloodless, $44.8 \%$ had minimal bleeding, and $6.9 \%$ had an acceptable level of bleeding. Both scar thickness and density were shown to have a significant relationship with operative field clarity $(\mathrm{P}<0.05)$.

Conclusions The one-per-million tumescent technique is effective in facilitating post-burn hand deformity surgeries involving meticulous, multiple, and lengthy procedures by creating a relatively clear operative field without the use of a tourniquet. Although scar thickness and density are associated with the clarity of the operative field, this technique can be considered safe and effective in creating a clear operative field.

Keywords Burns / Contracture / Cicatrix / Epinephrine / Hand

\section{Correspondence:}

Theddeus $\mathrm{OH}$ Prasetyono

Division of Plastic Surgery, Department of Surgery, Faculty of Medicine, University of Indonesia and Cipto Mangunkusumo Hospital, Medical Staff Building 4th floor Jl. Diponegoro,

71 Jakarta 13410, Indonesia

Tel: $+62-817858899$

Fax: +62-21-3905556

E-mail: teddyohprasetyono@yahoo.com
This article contains supplemental Tables $\mathrm{S} 1, \mathrm{~S} 2$, and Video S1.

No potential conflict of interest relevant to this article was reported.

\section{INTRODUCTION}

For centuries, tourniquets have been used to create clear operating fields in the extremities [1]. A pioneer in hand surgery, Ster- ling Bunnell, once said: "Operating on a hand without a tourniquet is like trying to fix a watch in a bottle of ink" [2]. Hence, it has become an established paradigm that tourniquet use is required in extremity surgery, including contracture release sur- 
gery for severely burned hands.

Burn scar excision is generally accompanied by significant blood loss $[3,4]$. This blood loss may be due to the higher vascularity of hypertrophic scar tissue compared to normal tissue [5]. Moreover, surgery for burn scars on the hand, with or without contracture, usually requires a relatively long amount of time (more than two hours) due to complex deformities in multiple digits and the tedious work of suturing the skin graft. This prolonged surgery can result in the prolonged use of a tourniquet, which has the potential to cause complications such as skin damage [6], pressure-induced nerve damage [6-8], and ischemic muscle damage [6]. To avoid such complications, alternative non-tourniquet techniques are a possibility for lengthy procedures.

Numerous studies have proven the safety of epinephrine with concentrations ranging from $1: 80,000$ to $1: 400,000$ in a tumescent solution when used for various upper extremity surgeries [9-14]. Our team $[15,16]$ has reported the use of a $1: 1,000,000$ (one-per-million) epinephrine tumescent formula. This concentration is very low compared to earlier studies involving a tumescent solution. Nonetheless, the one-per-million tumescent solution has been used in a wide variety of hand and upper extremity cases. However, no study has focused exclusively on the use of tumescent injections in post-burn hand deformity surgery. Thus, this study was carried out to determine the effectiveness of a technique using the one-per-million tumescent solution in post-burn hand deformity surgery.

\section{METHODS}

A case series was conducted on the application of the one-permillion tumescent technique in surgery on post-burn hand deformities without the use of a tourniquet. Information was taken from the medical records of all patients who underwent postburn hand deformity surgery from February 2013 to January 2014. This study protocol conformed to the principles outlined in the Declaration of Helsinki and received approval from the Institutional Review Board. We obtained written informed consent from each patient. Data were recorded on the clarity of the operative field, the quantity of the tumescent solution injected, the length of surgery, the assessment of the burn scar, and the functional outcomes. It was possible for one patient to have multiple operative fields.

The one-per-million tumescent solution was formulated as $1: 1,000,000$ epinephrine and $0.2 \%$ lidocaine in saline solution [15]. To obtain a bloodless surgical field, the tumescent solution was injected locally into the subcutaneous tissue and, if possible, the scar tissue until the skin area turned pale. Seven to
10 minutes after the last injection is mandatory waiting time before the first incision can be made.

The first author subjectively assessed the clarity of each operative field and then sorted them into four different categories: totally bloodless, minimal bleeding, acceptable bleeding, and bloody. A totally bloodless operative field was as bloodless as would have been achieved by pneumatic tourniquet use. Minimal bleeding refers to slight bleeding that does not affect the clarity of the operative field nor the ability to recognition of the anatomical structures. Acceptable bleeding includes bleeding that requires more gauze sweepings in order to keep the anatomical structures recognizable without causing difficulties to the surgeon performing the procedure. The last category, a bloody operative field, is defined as involving bleeding that disturbs the recognition of anatomical structures and requires the additional use of a pneumatic tourniquet [15].

The assessment of the thickness and density of burn scars was performed using modified Vancouver Scar Scale (VSS) categories. The thickness and density were assessed according to the VSS height and pliability categories, respectively [17]. Unlike the original VSS height measurement, which only measures the height of a burn scar from the surface level of surrounding normal skin, we assessed the scar thickness by summing the scar height both above and under the normal skin surface level. The thickness was categorized as thin, moderate, and thick. A thin burn scar was defined as having a depth of less than $2 \mathrm{~mm}$. A moderate burn scar was defined as a scar with a thickness of $2-5 \mathrm{~mm}$. Burn scars more than $5 \mathrm{~mm}$ thick were categorized as thick burn scars.

The density of burn scars was subjectively assessed. Burn scars were classified into three categories according to their density: pliable, moderate, and high. Pliable is equivalent to the VSS category of supple, implying a scar that yields with minimal resistance. Moderate density is similar to the VSS category of yielding, which means a yielding scar that has moderate resistance but does not form a solid mass. High density has the same meaning as the VSS category of firm, referring to a firm scar that moves as a solid inflexible unit [17]. The relationship of scar thickness and density with the clarity of the operative field was analyzed with the chi-square test.

To assess the outcome of the operations, we recorded overall function by measuring the range of motion of the respective hands, elbow, and axilla at least three months after each procedure. By modifying two range of motion assessment classifications as presented by Schwanholt et al. [18] and Schwarz [19], we sorted the final outcomes into four categories of overall active function: excellent, good, fair, and poor. Excellent function was defined as full extension ( 0 degrees) of all fingers, full to 170 degrees of elbow extension, and full to 170 degrees of axilla 
abduction. Good function was defined as finger flexion of five degrees at active extension, evidence of webbing, 130 to $170 \mathrm{de}$ grees of elbow extension, and 130 to 170 degrees of axilla abduction. Fair function was defined to include hands with flexion contractures from five to 30 degrees at active extension, 90 to 130 degrees of elbow extension, and 90 to 130 degrees of axilla abduction. Poor function was defined to include hands with flexion contracture over 30 degrees, elbow extensions of less than 90 degrees, and axilla abductions of less than 90 degrees.

Distinct criteria for evaluating abduction/hyperextension function were created to assess thumb abduction and any hyperextension of the fingers. Satisfactory function was defined as thumb abduction $\geq 50$ degrees and/or no finger hyperextension, while mediocre function was defined as thumb abduction $<50$ degrees and/or any degree of finger hyperextension (Supplemental Table S1).

\section{Fig. 1. Unification of adjacent operative fields}

Operative field 19 in patient 5 consisted of three operative fields on the right hand. The three operative fields were located adjacent to one another, resulting in the confluence of injections. Thus, the three operative fields were ultimately characterized as a single operative field with regard to the assessment of operative field clarity.

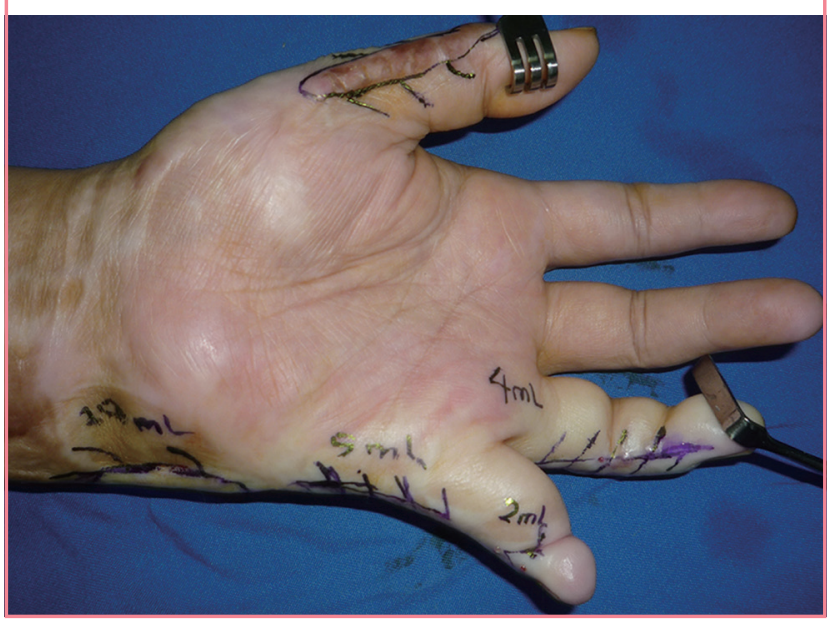

\section{RESULTS}

Overall, we treated 12 patients, including nine (75\%) males and three (25\%) females (Table 1), with various deformities due to burns on their hands and upper extremities. Their ages ranged from 1.3 years to 61 years, with an average of 19.9 years $(+19.182$ years).

Initially, 35 operative fields were analyzed. Six of them were modified in the individual analysis due to the confluent effect of the injected solution with the neighboring fields, as shown in Fig. 1. As those six operative fields were merged with the neighboring fields, a total of 29 operative fields were included in the final analysis.

Of the 29 operative fields, 14 (48.2\%) were totally bloodless, 13 (44.8\%) had minimal bleeding, two (6.9\%) had acceptable bleeding, and none had a bloody operative field. Fig. 2 shows an example of a totally bloodless operative field (Supplemental Vidoe $\mathrm{S} 1)$.

Measuring scar thickness showed that 16 (55.2\%) operative fields had thin scars, nine (31.0\%) had scars of moderate thickness, and four (13.8\%) had thick scars. As for scar density, 14 (48.3\%) operative fields contained pliable scars, 10 (34.5\%) involved scars of moderate density, and five (17.2\%) contained scars with high density (Supplemental Table S2).

All procedures were performed under general anesthesia. The surgery duration ranged from 80 to 450 minutes, with an average of 272.7 minutes ( \pm 143.260 minutes). The volume of tumescent solution used ranged from two to $128 \mathrm{~mL}$, with a median of $12 \mathrm{~mL}$. No additional tumescent injections were given during surgery.

Some flaps were created to release the contractures and cover the resulting defects, which included multiple z-plasties, web triangular flaps, and islanded flaps. Without including the z-plasties, there were seven local and regional flaps; six triangular flaps, and one islanded digital flap. None of these seven flaps under-

Fig. 2. A totally bloodless operative field

An example of a totally bloodless operative field, in patient 6, operative field 20. (A) The anatomical structures can be easily distinguished in this extensive operative field aimed at releasing elbow contracture. The operative field was designed for a procedure that would lengthen the biceps tendon. (B) An immediate postoperative picture shows a split thickness skin graft used to resurface the defect.
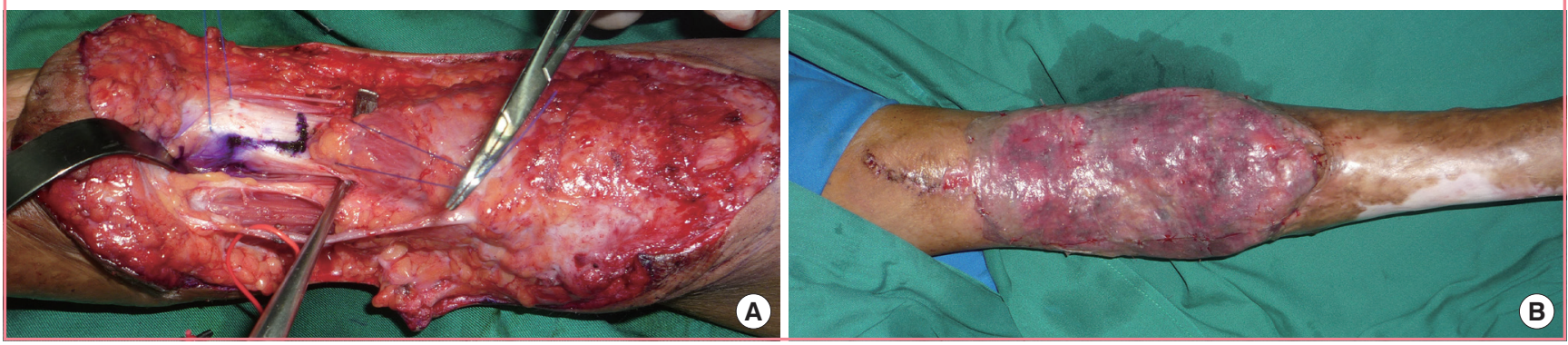


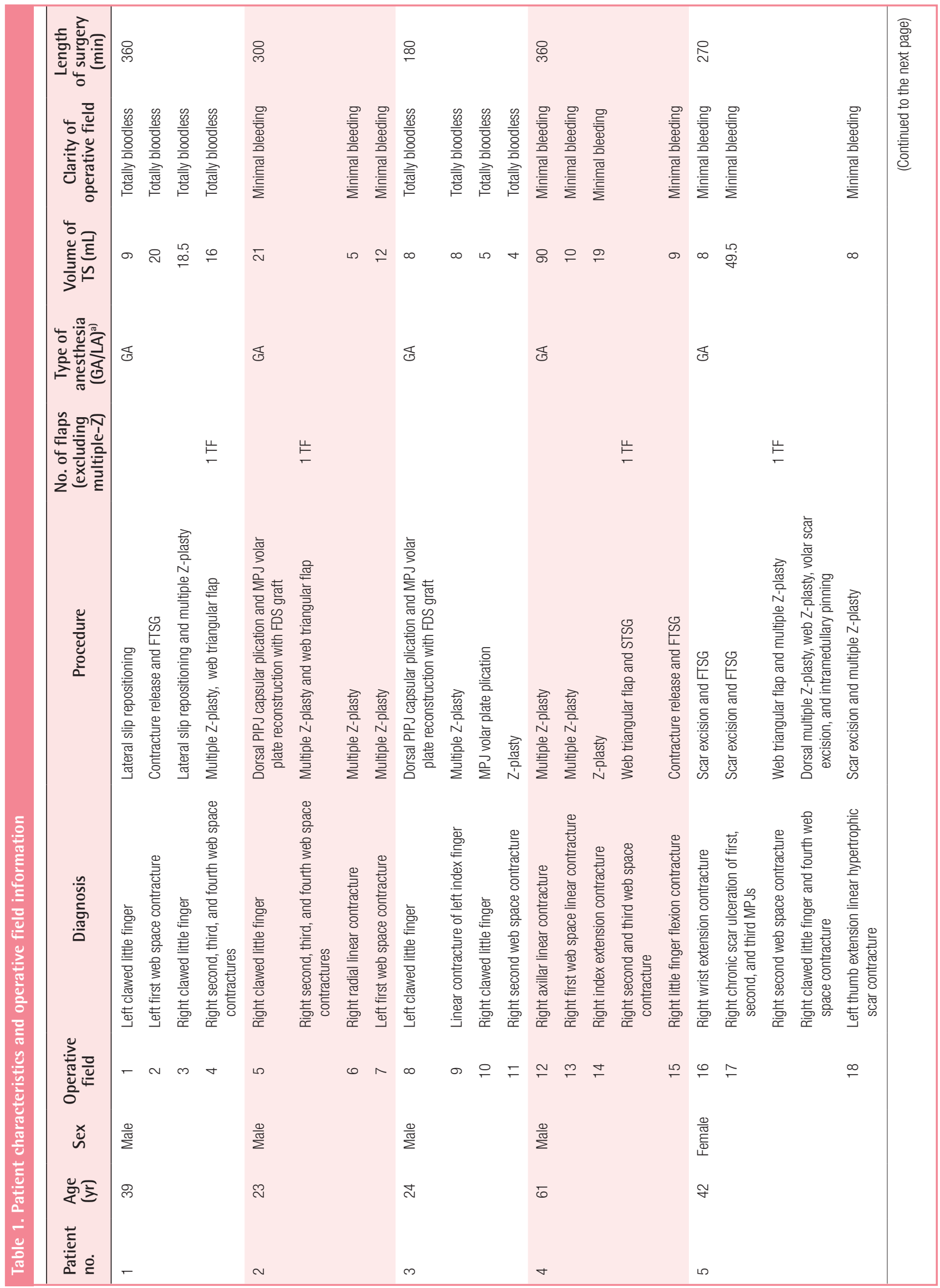




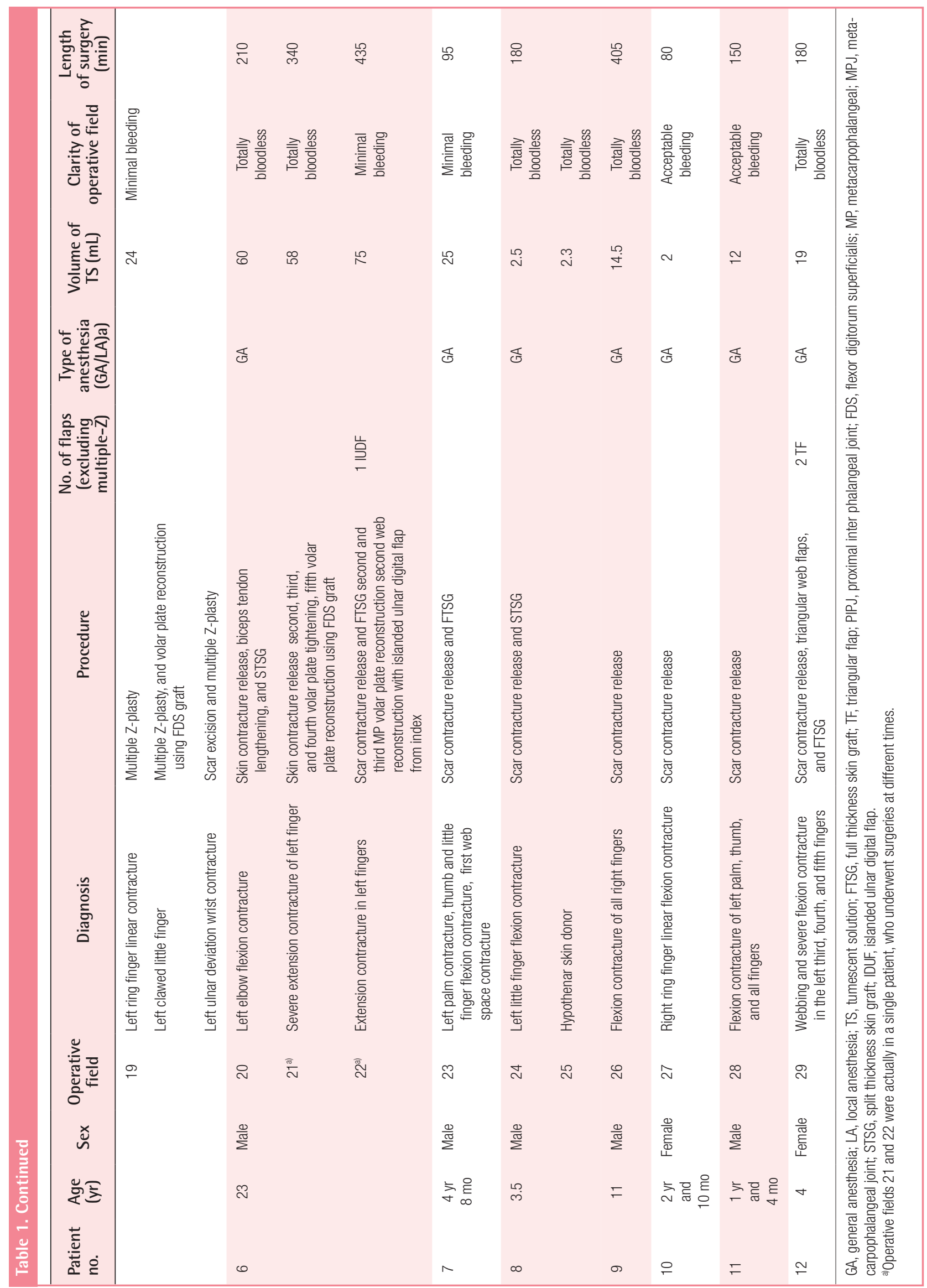




\begin{tabular}{|c|c|c|c|}
\hline \multirow[b]{2}{*}{ Variable } & \multicolumn{2}{|c|}{ Clarity of operative field } & \multirow[b]{2}{*}{ P-value } \\
\hline & $\begin{array}{c}\text { Totally } \\
\text { bloodless }\end{array}$ & $\begin{array}{c}\text { Minimum \& } \\
\text { acceptable } \\
\text { bleeding }\end{array}$ & \\
\hline Scar thickness & & & $<0.05$ \\
\hline Thin & 12 & 4 & \\
\hline Moderate \& thick & 2 & 11 & \\
\hline Scar density & & & $<0.05$ \\
\hline Pliable & 12 & 2 & \\
\hline Moderate \& high & 2 & 13 & \\
\hline
\end{tabular}

went necrosis.

The clarity of the operative field, scar thickness, and scar density were then adjusted by combining minimal and acceptable bleeding, moderate thickness scars with thick scars, and moderate density scars with high density scars. Table 2 describes the relationship of the clarity of the operative field to scar thickness and scar density.

Table 3 shows hand function before and after surgery. Data were only available from eight patients who presented 20 operative fields, whereas the data of the other four subjects with nine operative fields were not available. Among the 20 operative fields examined, the outcome of overall active function was excellent in five cases, good in one case, fair in one case, and poor in four cases. For abduction-hyperextension, there were eight outcomes with satisfactory function and one with mediocre function.

\section{DISCUSSION}

To our knowledge, no published studies have yet focused specifically on the use of tumescent solution in burn hand contracture surgery, although there have been some sporadic reports of surgeries with a broad range of diagnoses that did not use a tourniquet $[15,20]$. These reports do not specifically discuss the characteristics of the burn scars and how they influence the effectiveness of the tumescent technique. We have reported that only three out of 29 (10.3\%) burn contracture operative fields were totally bloodless, while the remaining cases involved minimal bleeding, except for one bloody operative field that was converted into a surgery with a tourniquet [15]. Interestingly, our current study shows different outcomes regarding the operative field clarity. Almost half of the cases in this study had totally bloodless operative fields and no case required the use of a tourniquet during surgery.

The duration of surgeries in this study was relatively long due to the complexity and severity of the cases. The longest surgery

\section{Fig. 3. Islanded ulnar digital flap patency}

A digital islanded flap (black arrow) was harvested from the ulnar side of the index finger to cover the second web space. The flap was performed in patient 6, operative field 22 .

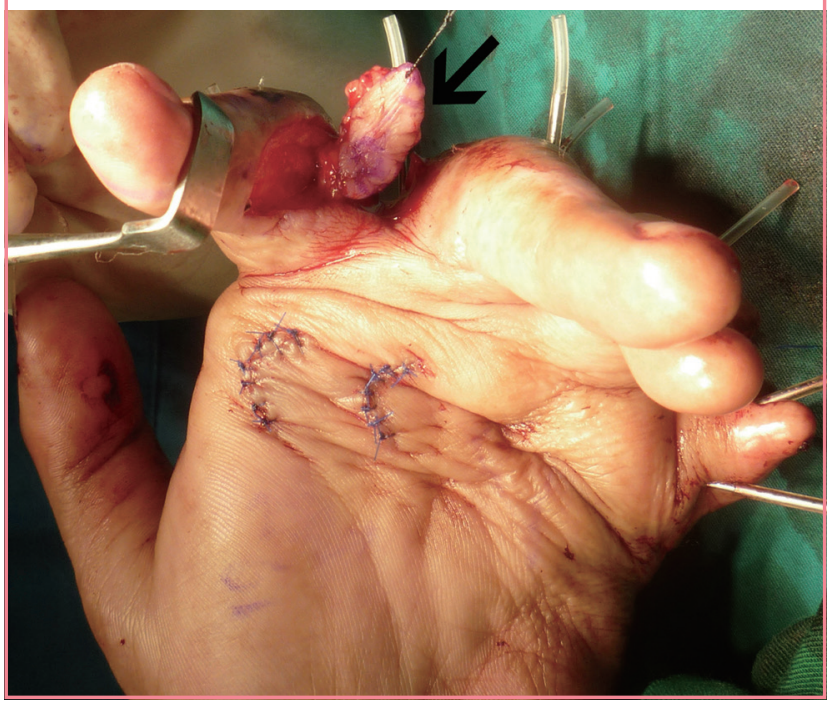

was 450 minutes long, whereas only two patients had procedures that took less than 120 minutes, which is the surgery duration that is the most commonly cited value for a safe tourniquet inflation period [21]. In a procedure lasting 450 minutes, it might be necessary to re-inflate the pneumatic tourniquet at least twice, which could potentially result in complications due to prolonged ischemia time. Thus, the one-per-million tumescent technique may help the surgeon to avoid lengthy and repeated tourniquet applications. Seven local and regional flaps were present in this study, and none showed any degree of necrosis. Even the islanded digital flap (Fig. 3), which rendered a perforator-based flap, successfully survived. This study therefore contributes more data on the safety of tumescent solution with regard to flap survivability.

It was found that out of the 14 totally bloodless operative fields, 12 cases involved thin burn scars with pliable density, while the remaining two cases were burn scars with moderate thickness and moderate density. Although burn scars in the minimal bleeding category were varied in their types of thickness and density categories, almost half of the operative fields had burn scars of moderate thickness and moderate density. All thick scars with high density produced acceptable bleeding, which provides the least clarity. Two conclusions can be drawn from these findings. First, a thin scar is approximately 11 times more likely to develop a bloodless operative field than scars of moderate thickness and thick scars (likelihood ratio $=11.011$ ) are. This relationship between operative field clarity and scar thickness was found to be statistically significant. Second, the 


\begin{tabular}{|c|c|c|}
\hline $\begin{array}{l}\text { No. of } \\
\text { operative } \\
\text { field }\end{array}$ & Diagnosis & $\begin{array}{l}\text { Flexion and extension } \\
\text { functionality before surgery }\end{array}$ \\
\hline
\end{tabular}

Outcomes

\begin{tabular}{cc}
\multicolumn{2}{c}{ Outcomes } \\
\hline $\begin{array}{c}\text { Flexion and extension } \\
\text { functionality }\end{array}$ & $\begin{array}{c}\text { Overall function/ } \\
\text { Abduction- } \\
\text { hyperextension }\end{array}$
\end{tabular}

hyperextension

\begin{tabular}{|c|c|c|c|c|}
\hline 1 & Left clawed little finger & Hyperextension of PIPJ & No hyperextension of PIPJ & Satisfactory \\
\hline 2 & Left first web space contracture & Thumb abduction $45^{\circ}$ & Thumb abduction $60^{\circ}$ & Satisfactory \\
\hline 3 & Right clawed little finger & Hyperextension of MPJ and flexion of PIPJ & $\begin{array}{l}\text { Full flexion and extension of MPJ and } \\
\text { PIPJ of right little finger }\end{array}$ & Excellent \\
\hline 4 & $\begin{array}{l}\text { Right second, third, and fourth web space } \\
\text { contractures }\end{array}$ & Limited abduction of right fingers & Full abduction of right fingers & Excellent \\
\hline \multirow[t]{2}{*}{5} & Right clawed little finger & Hyperextension of MPJ and flexion of PIPJ & $\begin{array}{l}\text { Right little finger PIPJ flexion } 120^{\circ} \text {, } \\
\text { no hyperextension of MPJ }\end{array}$ & Poor \\
\hline & $\begin{array}{l}\text { Right second, third, fourth web space } \\
\text { contractures }\end{array}$ & Limited abduction of fingers & Full abduction of fingers & \\
\hline 6 & Right radial linear thumb contracture & Limited thumb extension & Full thumb extension & Satisfactory \\
\hline 7 & Left first web space contracture & Thumb abduction $40^{\circ}$ & Thumb abduction $80^{\circ}$ & Satisfactory \\
\hline 8 & Left clawed little finger & Hyperextension of MPJ and flexion of PIPJ & $\begin{array}{l}\text { No hyperextension and full flexion of MPJ in } \\
\text { little finger, full flexion of PIPJ }\end{array}$ & Excellent \\
\hline 9 & Linear contracture of left index finger & Limited finger extension & Extension of PIPJ $160^{\circ}$ & Fair \\
\hline 10 & Right clawed little finger & Hyperextension of MPJ & No hyperextension of MPJ & Satisfactory \\
\hline 11 & Right second web space contracture & Limited abduction of fingers & Full second finger abduction & Excellent \\
\hline 12 & Right axillar linear contracture & $90^{\circ}$ abduction and $90^{\circ}$ extension of axilla & $150^{\circ}$ arm abduction and $180^{\circ}$ extension & Good \\
\hline 13 & Right first web space linear contracture & $80^{\circ}$ thumb abduction & $90^{\circ}$ thumb abduction & Satisfactory \\
\hline \multirow[t]{2}{*}{14} & Right index extension contracture & $30^{\circ}$ PIPJ flexion & $90^{\circ} \mathrm{PIPJ}$ flexion & Poor \\
\hline & $\begin{array}{l}\text { Right second and third web space } \\
\text { contracture }\end{array}$ & Limited abduction of fingers & $30^{\circ}$ abduction of fingers & Poor \\
\hline 15 & Right little finger flexion contracture & $30^{\circ}$ PIPJ extension & $120^{\circ}$ PIPJ extension & Poor \\
\hline 16 & Right wrist extension contracture & $45^{\circ}$ wrist flexion & Not available & Not available \\
\hline \multirow[t]{3}{*}{17} & $\begin{array}{l}\text { Right chronic scar ulceration of first, } \\
\text { second, and third MPJs }\end{array}$ & $60^{\circ}$ flexion of MPJs with chronic scarring & Not available & Not available \\
\hline & Right second web space contracture & Limited abduction of fingers & Not available & Not available \\
\hline & $\begin{array}{l}\text { Right clawed little finger and fourth web } \\
\text { space contracture }\end{array}$ & Hyperextension of MPJ and flexion of PIPJ & Not available & Not available \\
\hline 18 & $\begin{array}{l}\text { Left thumb extension linear hypertrophic } \\
\text { scar contracture }\end{array}$ & Limited thumb flexion & Not available & Not available \\
\hline \multirow[t]{3}{*}{19} & Left ring finger linear contracture & Limited finger extension & Not available & Not available \\
\hline & Left clawed little finger & Hyperextension of MPJ and flexion of PIPJ & Not available & Not available \\
\hline & Left ulnar deviation wrist contracture & Limited wrist radial deviation & Not available & Not available \\
\hline 20 & Left elbow flexion contracture & $80^{\circ}$ elbow extension & $175^{\circ}$ elbow extension & Excellent \\
\hline 21 & Severe extension contracture ${ }^{a)}$ of left fingers & $\begin{array}{l}90^{\circ}-130^{\circ} \text { hyperextension in second to } \\
\text { fifth MPJ }\end{array}$ & $\begin{array}{l}45^{\circ}-60^{\circ} \text { hyperextension in second to } \\
\text { fifth MPJ }\end{array}$ & Mediocre \\
\hline 22 & Extension contracture ${ }^{a}$ in left fingers & $\begin{array}{l}45^{\circ}-60^{\circ} \text { hyperextension in second to } \\
\text { fifth MPJ }\end{array}$ & Not available & Not available \\
\hline 23 & $\begin{array}{l}\text { Left palm contracture, thumb and little } \\
\text { finger flexion contracture, and first web } \\
\text { space contracture }\end{array}$ & $\begin{array}{l}\text { Limited extension of second, third, and } \\
\text { fourth MPJ; IPJs extension of thumb and } \\
\text { little finger; and thumb abduction }\end{array}$ & $\begin{array}{l}\text { Full extension of all fingers and } 80^{\circ} \text { thumb } \\
\text { abduction }\end{array}$ & Satisfactory \\
\hline 24 & Left little finger flexion contracture & $\begin{array}{l}\text { Limited extension ( } 90^{\circ} \text { PIPJ extension, } \\
\text { ulnar rotation) }\end{array}$ & Not available & Not available \\
\hline 25 & Hypothenar skin donor & Skin harvest (skin area with burn scar) & Not available & Not available \\
\hline 26 & Flexion contracture of all right fingers & Limited extension of all fingers & Not available & Not available \\
\hline 27 & Right ring finger linear flexion contracture & Limited extension & Not available & Not available \\
\hline 28 & $\begin{array}{l}\text { Flexion contracture of left palm, thumb, } \\
\text { and all fingers }\end{array}$ & $\begin{array}{l}\text { Limited palm opening, } 80^{\circ} \text { thumb abduction, } \\
80^{\circ} \text { second and fourth MPJ extension, } \\
85^{\circ} \text { third and fifth MPJ extension }\end{array}$ & $\begin{array}{l}\text { Limited palm opening, } 85^{\circ} \text { thumb } \\
\text { abduction, full extension of second to } \\
\text { fifth MPJ }\end{array}$ & Satisfactory \\
\hline 29 & $\begin{array}{l}\text { Webbing and severe flexion contracture in } \\
\text { the left third, fourth, and fifth fingers }\end{array}$ & Severe flexion and adduction & $\begin{array}{l}\text { Full extension of left third finger, full passive } \\
\text { extension of fourth finger, severe flexion } \\
\text { of fifth finger, and full abduction of fingers }\end{array}$ & $\begin{array}{l}\text { Poor } \\
\text { (on the fifth finger) }\end{array}$ \\
\hline
\end{tabular}

PIPJ, proximal inter phalangeal joint; MPJ, metacarpophalangeal joint; IPJ, inter phalangeal joint.

${ }^{a}$ Operative fields 21 and 22 were actually in a single patient, who underwent surgeries at different times. 
probability of pliable scars developing a bloodless operative field is 17 times higher than that of moderate and high-density scars (likelihood ratio $=16.905)$ are. This was also found to be statistically significant.

Out of the 20 operative fields for which follow-up was possible, 15 had adequate function of flexion and extension, one (operative field 21) was categorized as mediocre, and four (operative fields 5, 14, 15, and 29) were considered poor. Two out of the four poor outcomes (operative fields 14 and 15) and one mediocre outcome actually reflected an improvement in the patient's condition, with range of motion improvement ranging from 45 to 90 degrees. Despite the full correction of hyperextension of the metatarsophalangeal joint, the outcome of operative field 5 was still considered poor because the range of motion of the proximal interphalangeal joint did not improve. The last operative field with a poor outcome (operative field 29) preoperatively presented with a severe flexion and an adduction contracture in the third to fifth fingers. Even though full abduction and extension of the third and fourth fingers were achieved, the fifth finger could not be corrected due to diminished distal vascularization that occurred while it was being straightened. Therefore, this outcome was categorized as poor. However, the problem involving vascularization was likely not related to the use of the tumescent technique, as the finger returned to its normal vascularization after the removal of the $\mathrm{K}$-wire. It seems that the cause was merely physical intolerance in the vessels due to mechanical straightening.

In summary, the one-per-million tumescent technique effectively creates a relatively clear operative field without the use of a tourniquet in surgeries for post-burn hand deformities, especially in meticulous, multiple, and lengthy procedures. Although scar thickness and density affect its implementation, this technique can be considered safe and effective in creating a clear operative field. Nevertheless, this study has several drawbacks. First, it was conducted without a control group; hence, the effectiveness of the tumescent technique could not be directly compared to the pneumatic tourniquet. Second, burn scar thickness was measured intraoperatively through the surgical wound. This means that the swelling effect of the injection was also included in the thickness measurement. The last drawback is that the clarity of the operative field and the density of the burn scar were assessed subjectively.

\section{REFERENCES}

1. Karia RA. Hemostasis and tourniquet. Oper Tech Sports Med 2011;19:224-30.

2. Flatt AE. Tourniquet time in hand surgery. Arch Surg 1972;
104:190-2.

3. Robertson RD, Bond P, Wallace B, et al. The tumescent technique to significantly reduce blood loss during burn surgery. Burns 2001;27:835-8.

4. Cartotto R, Musgrave MA, Beveridge M, et al. Minimizing blood loss in burn surgery. J Trauma 2000;49:1034-9.

5. van der Veer WM, Bloemen MC, Ulrich MM, et al. Potential cellular and molecular causes of hypertrophic scar formation. Burns 2009;35:15-29.

6. Oragui E, Parsons A, White T, et al. Tourniquet use in upper limb surgery. Hand (N Y) 2011;6:165-73.

7. Avci G, Akan M, Yildirim S, et al. Digital neurovascular compression due to a forgotten tourniquet. Hand Surg 2003;8: 133-6.

8. Odinsson A, Finsen V. Tourniquet use and its complications in Norway.J Bone Joint Surg Br 2006;88:1090-2.

9. Denkler K. A comprehensive review of epinephrine in the finger: to do or not to do. Plast Reconstr Surg 2001;108: 114-24.

10. Wilhelmi BJ, Blackwell SJ, Miller JH, et al. Do not use epinephrine in digital blocks: myth or truth? Plast Reconstr Surg 2001;107:393-7.

11. Denkler K. Dupuytren's fasciectomies in 60 consecutive digits using lidocaine with epinephrine and no tourniquet. Plast Reconstr Surg 2005;115:802-10.

12. Chowdhry S, Seidenstricker L, Cooney DS, et al. Do not use epinephrine in digital blocks: myth or truth? Part II. A retrospective review of 1111 cases. Plast Reconstr Surg 2010; 126:2031-4.

13. Thomson CJ, Lalonde DH, Denkler KA, et al. A critical look at the evidence for and against elective epinephrine use in the finger. Plast Reconstr Surg 2007;119:260-6.

14. Lalonde DH, Lalonde JF. Discussion. Do not use epinephrine in digital blocks: myth or truth? Part II. A retrospective review of 1111 cases. Plast Reconstr Surg 2010;126:2035-6.

15. Prasetyono TO, Biben JA. One-per-mil tumescent technique for upper extremity surgeries: broadening the indication. J Hand Surg Am 2014;39:3-12.e7.

16. Prasetyono TH, Saputra DA, Astriana W. One-per-mil tumescent technique for bone and joint surgery in hand. HAND 2014:1-5.

17. Sullivan T, Smith J, Kermode J, et al. Rating the burn scar. J Burn Care Rehabil 1990;11:256-60.

18. Schwanholt C, Greenhalgh DG, Warden GD. A comparison of full-thickness versus split-thickness autografts for the coverage of deep palm burns in the very young pediatric patient. J Burn Care Rehabil 1993;14:29-33.

19. Schwarz RJ. Management of postburn contractures of the 
upper extremity. J Burn Care Res 2007;28:212-9.

20. Prasetyono TO. Tourniquet-free hand surgery using the oneper-mil tumescent technique. Arch Plast Surg 2013;40:129-33.
21. Cox $C$, Yao J. Tourniquet usage in upper extremity surgery. $J$ Hand Surg Am 2010;35:1360-1.

Supplemental Table S1. Summary of categories definition

Supplemental data can be found at: http://e-aps.org/src/sm/aps-42-164-s001.pdf

Supplemental Table S2. Operative field distribution based on the thickness and density of scar

Supplemental data can be found at: http://e-aps.org/src/sm/aps-42-164-s002.pdf

Supplemental Video S1. One-per-mil tumescent technique in hand burn surgery.

Supplemental data can be found at: http://e-aps.org/src/sm/aps-42-164-s003.mp4 


\section{Supplemental Table S1. Summary of categories definition}

\begin{tabular}{|c|c|c|c|}
\hline \multicolumn{2}{|l|}{ Categories } & Sub-categories & Definition \\
\hline \multirow{4}{*}{\multicolumn{2}{|c|}{ Clarity of operative field }} & Totally bloodless & A bloodless operative field equal to that achieved by pneumatic tourniquet use \\
\hline & & Minimal bleeding & $\begin{array}{l}\text { Slight bleeding that does not affect the clarity of the operative field and the } \\
\text { recognition of the anatomical structures }\end{array}$ \\
\hline & & Acceptable bleeding & $\begin{array}{l}\text { Bleeding that needs more gauze sweeping in order to keep the anatomical } \\
\text { structure recognizable without rendering difficulties to the surgeon } \\
\text { performing the procedures }\end{array}$ \\
\hline & & Bloody & $\begin{array}{l}\text { Bleeding that disturbs the recognition of anatomical structures and needs } \\
\text { additional use of pneumatic tourniquet }\end{array}$ \\
\hline \multirow{3}{*}{\multicolumn{2}{|c|}{ Scar thickness }} & Thin & Scar which thickness is less than $2 \mathrm{~mm}$ \\
\hline & & Moderate & Scar which has a thickness of $2-5 \mathrm{~mm}$ \\
\hline & & Thick & Scar which thickness is more than $5 \mathrm{~mm}$ \\
\hline \multirow{3}{*}{\multicolumn{2}{|c|}{ Scar density }} & Pliable & Scar that yields with minimal resistance \\
\hline & & Moderate & A yielding scar with moderate resistance but does not form a solid mass \\
\hline & & High & A firm scar that moves as a solid inflexible unit \\
\hline \multirow[t]{6}{*}{ Functional outcome } & $\begin{array}{l}\text { Overall function } \\
\text { (finger extension, elbow extension, } \\
\text { and axilla abduction) }\end{array}$ & Excellent & $\begin{array}{l}\text { Full extension ( } 0 \text { degree) of all fingers, full to } 170 \text { degrees of elbow extension, } \\
\text { and full to } 170 \text { degrees of axilla abduction }\end{array}$ \\
\hline & & Good & $\begin{array}{l}\text { Finger flexion of } 5 \text { degrees at active extension, evidence of webbing, } 130 \text { to } \\
170 \text { degrees of elbow extension, and } 130 \text { to } 170 \text { degrees of axilla abduction. }\end{array}$ \\
\hline & & Fair & $\begin{array}{l}\text { Finger flexion from } 5 \text { to } 30 \text { degrees at active extension, } 90 \text { to } 130 \text { degrees of } \\
\text { elbow extension, and } 90 \text { to } 130 \text { degrees of axilla abduction }\end{array}$ \\
\hline & & Poor & $\begin{array}{l}\text { Finger flexion over } 30 \text { degrees, less than } 90 \text { degrees of elbow extensions, } \\
\text { and less than } 90 \text { degrees of axilla abduction }\end{array}$ \\
\hline & $\begin{array}{l}\text { Abduction-hyperextension } \\
\text { (thumb abduction and finger } \\
\text { hyperextension) }\end{array}$ & Nice & Thumb abduction $>50$ degrees and/ or no finger hyperextension \\
\hline & & Mediocre & Thumb abduction $<50$ degrees and/ or any degree of finger hyperextension \\
\hline
\end{tabular}


Supplemental Table S2. Operative field distribution based on the thickness and density of scar

\begin{tabular}{|c|c|c|c|c|c|c|c|c|c|c|}
\hline \multirow{2}{*}{$\begin{array}{l}\text { Clarity of } \\
\text { operative field }\end{array}$} & \multirow{2}{*}{$\begin{array}{l}\text { Scar thickness: } \\
\text { Scar density: }\end{array}$} & \multicolumn{3}{|c|}{ Thin } & \multicolumn{3}{|c|}{ Moderate } & \multicolumn{3}{|c|}{ Thick } \\
\hline & & Pliable & Moderate & High & Pliable & Moderate & High & Pliable & Moderate & High \\
\hline Totally bloodless & & 12 & 0 & 0 & 0 & 2 & 0 & 0 & 0 & 0 \\
\hline Minimum bleeding & & 2 & 2 & 0 & 0 & 6 & 1 & 0 & 0 & 2 \\
\hline Acceptable bleeding & & 0 & 0 & 0 & 0 & 0 & 0 & 0 & 0 & 2 \\
\hline
\end{tabular}

